\title{
Degradation of common pharmaceuticals and personal care products in mixed solutions by advanced oxidation techniques
}

\author{
*R. R. Giri; H. Ozaki; S. Ota; R. Takanami; S. Taniguchi
}

Osaka Sangyo University, 3-1-1 Nakagaito, Daito City, 574-8530 Osaka, Japan

Received 11 November 2009; $\quad$ revised 4 February 2010; accepted 23 February 2010; avaiable online 1 March 2010

\begin{abstract}
Widespread detection of pharmaceutical compounds in water environment has been a serious concern recently, while conventional sewage treatments are ineffective for their elimination. But, advanced oxidation techniques are very promising to remove varieties of organic contaminants in water. This research aims to elucidate oxidation potentials of sixteen commonly used pharmaceutical compounds in mixed solutions by seven advanced oxidation techniques in laboratory batch experiments. The removal profiles exhibited four distinct patterns: a) easily degradable by all seven techniques, b) not easily degradable by all seven techniques, c) easily degradable by ozone-based techniques, but not by ultraviolet radiation-based techniques and d) easily degradable by ultraviolet radiation-based techniques, but not by ozone-based techniques. Ozone-based techniques rather than ultraviolet radiation-based techniques were very powerful for simultaneous removal of the compounds efficiently. Moreover, ozonation combined with ultraviolet radiation was the most appropriate technique for simultaneous removal of the tested compounds efficiently. Increased ozone dissolution and decomposition with ozone-based techniques did not always enhance the compounds' removal. Physicochemical properties of the compounds and solution $\mathrm{pH}$ also presumably played an important role on the removal which merits further attention.
\end{abstract}

Keywords: Degradation rate; Hydroxyl radical; Ozone-based methods; Photodegradation; Ultra violet based methods

\section{INTRODUCTION}

Presence of pharmaceuticals and personal care products (PPCPs) particularly in sewage effluents, and ineffectiveness of conventional methods to remove the compounds has been a major concern in wastewater treatment. Detection of PPCPs in trace concentrations both in groundwater (Ikehata et al., 2006) and surface waters (Jasim et al., 2006) are reported worldwide. Various oxidation techniques have been tested to eliminate trace organic contaminants including PPCPs in water. Ozonation $\left(\mathrm{O}_{3}\right)$ and $\mathrm{O}_{3}$-based advanced oxidation processes (AOPs) are the most commonly investigated methods for the elimination (Ternes et al., 2003; Ikehata et al., 2006; Jasim et al., 2006; Snyder et al., 2006) while ultraviolet (UV) irradiation and UVbased AOPs are in the second place (Doll and Frimmel, 2005; Lin and Reinhard, 2005; Dalrymple et al., 2007; Pereira et al., 2007a). Applications of $\mathrm{O}_{3}$ and UV-based oxidation methods for elimination of an individual pharmaceutical or mixture of a few pharmaceuticals in water have been the main focus of most of the $\bar{\triangle}$ *Corresponding Author Email: rabindra@cnt.osaka-andai.ac.jp Tel. +8172 875 3001, Fax: +8172 8753076 investigations conducted (Vonga et al., 2004; Calza et al., 2006; Pereira et al., 2007a,b). Removal of PPCPs by $\mathrm{O}_{3}, \mathrm{UV}, \mathrm{O}_{3} / \mathrm{UV}$ and $\mathrm{UV} / \mathrm{H}_{2} \mathrm{O}_{2}$ was characterized by pseudo first-order reaction kinetic (Das et al., 2008; Kim et al., 2008). Ozonation was found to be a very effective method to remove trace level carbamazepine and ibuprofen in water (Ikehata et al., 2006; Jasim et al., 2006). Canonica et al. (2008) pointed out $\mathrm{pH}$ dependence of photodegradation of pharmaceuticals. Lin and Reinhard (2005) found enhanced photodegradation of gemfibrozil, naproxen and ibuprofen in oxygen atmosphere. Several investigations focused on $\mathrm{UV} / \mathrm{H}_{2} \mathrm{O}_{2}$ method to remove particularly industrial dyes. Snyder et al. (2006), Samarghandi et al., (2007) and Malakootian et al., (2009) concluded that addition of hydrogen peroxide in ozonation was of little use to enhance removal of pharmaceuticals. Medium pressure UV lamps were found superior to low pressure lamps to degrade pharmaceuticals by both UV photolysis and $\mathrm{UV} / \mathrm{H}_{2} \mathrm{O}_{2}$ process (Pereira et al., 2007a). Photocatalysis also was found to be a promising method for oxidation of 
carbamazepine and clofibric acid in water (Doll and Frimmel, 2005; Giri et al., 2008).

Organic compounds particularly PPCPs in urban sewage, conventional sewage treatment plant effluents and effluents from agricultural and livestock farming facilities normally exist in complex water matrices. Removal of a PPCP coexisting with several similar compounds may not be the same as its removal in absence of the coexisting compounds. Some investigations have been carried out on removals of PPCPs in mixed solutions by AOPs (Jasim et al., 2006; Snyder et al., 2006; Kim et al., 2008), but removal characteristics of many PPCPs are not well understood. This article aimed to compare and discuss removals of fourteen commonly used pharmaceutical compounds (clofibric acid: CA, clarithromycin: CAM, carbamazepine: CBZ, diclofenac: DCF, fenoprofen: FEP, gemfibrozil: GFZ, ibuprofen: IBP, indomethacin: IDM, isopropylantipyrine: IPA, ketoprofen: KEP, naproxen: NPX, phenobarbital: PB, phenacetine: PNC and phenytoin: PNT) and two personal care products (triclocarban: TCC and triclosan: TCS) in mixed aqueous solutions (laboratory-grade water) using various oxidation techniques (ozonation: $\mathrm{O}_{3}, \mathrm{TiO}_{2}$-catalyzed ozonation: $\mathrm{O}_{3} / \mathrm{TiO}_{2}$, UV irradiation: $\mathrm{UV}, \mathrm{O}_{3}$ combined with UV: $\mathrm{O}_{3} / \mathrm{UV}$, photocatalysis: $\mathrm{UV} / \mathrm{TiO}_{2}, \mathrm{UV}$ combined with $\mathrm{H}_{2} \mathrm{O}_{2}: \mathrm{UV} / \mathrm{H}_{2} \mathrm{O}_{2}$ and photocatalytic ozonation: $\mathrm{O}_{3} /$ $\mathrm{UV} / \mathrm{TiO}_{2}$ ) in laboratory batch experiments. The experiments were carried out in the laboratory of New Industrial R and D Center, Osaka Sangyo University, during December 2008 to June 2009.

\section{MATERIALS AND METHODS}

IBP and TCC standards were purchased from SigmaAldrich Inc. and Tokyo Chemical Industry Co. Ltd., respectively. FEP, GFZ and CA standards were purchased from ICN Biomedicals Inc., LKT Lab Inc. and MP Biomedicals Inc., respectively. Other PPCPs, liquid $\mathrm{H}_{2} \mathrm{O}_{2}$ (30 \% by weight) and $\mathrm{Na}_{2} \mathrm{SO}_{3}$ (for quenching residual ozone in samples) were purchased from Wako Pure Chemicals Ltd. A low power (10 W) low pressure tubular mercury lamp (UVL10D, 254 nm, Sen Light Corporation, Japan) was the source of UV irradiation. Ozone generation, reactor design and details of the experimental setup are mentioned elsewhere (Giri et al., 2007). Carrier gas flow rate and ozone concentration in the gas were maintained at $1.0 \mathrm{~L} / \mathrm{min}$ and $2.0 \mathrm{mg} / \mathrm{L}$ in oxidations involving ozonation. High strength $\mathrm{TiO}_{2}$ fiber catalyst (fiber diameter: $8.0 \mu \mathrm{m}, 20 \mathrm{~cm} \times 20 \mathrm{~cm}$ sheets) was supplied by Ube Industries Ltd., Japan. The catalyst was uniformly placed and rigidly supported to inner surface of a cylindrical module (outer diameter (OD): $10.4 \mathrm{~cm}, \mathrm{H}: 18.2 \mathrm{~cm}$ ) made of stainless steel wire mesh ( $3 \mathrm{~mm} \times 3 \mathrm{~mm}$ opening) and fitted exactly to inner surface of glass reactor. A recirculation cooler (CCA-111, Tokyo Rikakikai Co., Ltd.) was employed for maintaining temperature of reaction solution.

\section{Experimental}

Stock solution of each PPCP $(1.0 \mathrm{~g} / \mathrm{L})$ was prepared in distilled-deionized water (ddw) and stored at $4{ }^{\circ} \mathrm{C}$ for future use. Mixed aqueous solutions $(1.2 \mathrm{~L})$ of the sixteen PPCPs (1.0 mg/L of each PPCP) were prepared in ddw using the stock solutions. The catalyst module was inserted into the reactor in experiments involving $\mathrm{TiO}_{2}$-catalyzed oxidations. Appropriate amount of $\mathrm{H}_{2} \mathrm{O}_{2}$ (11.03 $\mathrm{mM}$ initial concentration) was added into the reactor and mixed well before $\mathrm{UV} / \mathrm{H}_{2} \mathrm{O}_{2}$ experiments started. The initial $\mathrm{H}_{2} \mathrm{O}_{2}$ concentration $(11.03 \mathrm{mM})$ in $\mathrm{UV} / \mathrm{H}_{2} \mathrm{O}_{2}$ process was decided based on a series of preliminary PPCPs degradation experiments. The reaction solution was continuously mixed using a magnetic stirrer and bar $(\approx 300 \mathrm{rpm})$ under controlled temperature $\left(25 \pm 2{ }^{\circ} \mathrm{C}\right)$ in all the experiments. Solution $\mathrm{pH}$ values in any of the experiments were not adjusted. Samples were drawn at specified time intervals and analyzed for residual $\mathrm{H}_{2} \mathrm{O}_{2}$ and dissolved ozone and remaining PPCPs. Dissolved residual ozone and $\mathrm{H}_{2} \mathrm{O}_{2}$ in samples were quenched using $\mathrm{Na}_{2} \mathrm{SO}_{3}$ solution in ddw $(1.0 \mathrm{~g} / \mathrm{L})$. Other details on experimental procedure can be found elsewhere (Giri et al., 2007).

\section{Analyses}

Remaining PPCPs in samples were measured using liquid chromatography tandem mass spectrometry (LCMS/MS, applied biosystems). A turbo ion spray interface was used as the ion source and mass detection was carried out using multiple reactions monitoring (MRM) mode. Eleven PPCPs (CA, DCF, FEP, GFZ, IBP, IDM, NPX, PB, PNT, TCC and TCS) were scanned in negative ion mode while the remaining (CAM, CBZ, KEP, IPA and PNC) were scanned in positive ion mode. Nitrogen was used as collision and curtain gas. Air was used as nebulizer and dryer gas. Ion source voltages in negative and positive scan modes were -4500.0 and 5000.0, respectively, while dryer gas temperatures for the two cases were 400 and 
$500{ }^{\circ} \mathrm{C}$, respectively. The LC system consisted of a binary pump, an auto sampler and a degasser unit (Agilent 1100 series). Chromatographic separation was performed using ZORBAX Eclipse XDB-C18 column $(2.1 \times 150 \mathrm{~mm}, 3.5 \mu \mathrm{m})$ with $200 \mu \mathrm{L} / \mathrm{min}$ mobile phase flow rate, $10 \mu \mathrm{L}$ sample injection volume and column temperature fixed at $40^{\circ} \mathrm{C}$. Mobile phases for negative scan mode were: $0.1 \%(\mathrm{v} / \mathrm{v})$ acetic acid in $2.0 \mathrm{mM}$ ammonium acetate in ddw (A) and acetonitrile (B), while $0.1 \%(\mathrm{v} / \mathrm{v})$ formic acid in ddw and acetonitrile respectively were $\mathrm{A}$ and $\mathrm{B}$ in case of positive scan mode. Flow rate for A was set to $90 \%$ from 0 to $2 \mathrm{~min}$, which linearly decreased to $0 \%$ at $7 \mathrm{~min}$ and the same continued until $15 \mathrm{~min}$. Then the value increased again to $90 \%$ at $15.1 \mathrm{~min}$ and continued the same until the end (i.e. $20 \mathrm{~min}$ ). Photometric DPD (diphenylendiamine)-based method was used to measure residual aqueous phase ozone at $528 \mathrm{~nm}$ UV wavelength.

\section{RESULTS AND DISCUSSION}

Solution $p H$

Initial $\mathrm{pH}$ values of reaction solutions with $\mathrm{UV}, \mathrm{O}_{3}$ and $\mathrm{O}_{3} / \mathrm{UV}$ varied between 4.65 and 4.75 . The values with $\mathrm{UV} / \mathrm{H}_{2} \mathrm{O}_{2}$ were relatively bigger $(\approx 5.0)$ and more large values $(5.26 \sim 5.30)$ were observed with $\mathrm{TiO}_{2}$ fiber $\left(\mathrm{UV} / \mathrm{TiO}_{2}, \mathrm{O}_{3} / \mathrm{TiO}_{2}\right.$ and $\mathrm{O}_{3} / \mathrm{UV} / \mathrm{TiO}_{2}$ ). The initial $\mathrm{pH}$ values for all the cases decreased with increasing reaction time (Fig. 1), which is attributed to formation of organic acids (Vonga et al., 2004; Rosal et al., 2008). Therefore, decrease in solution $\mathrm{pH}$ may be considered

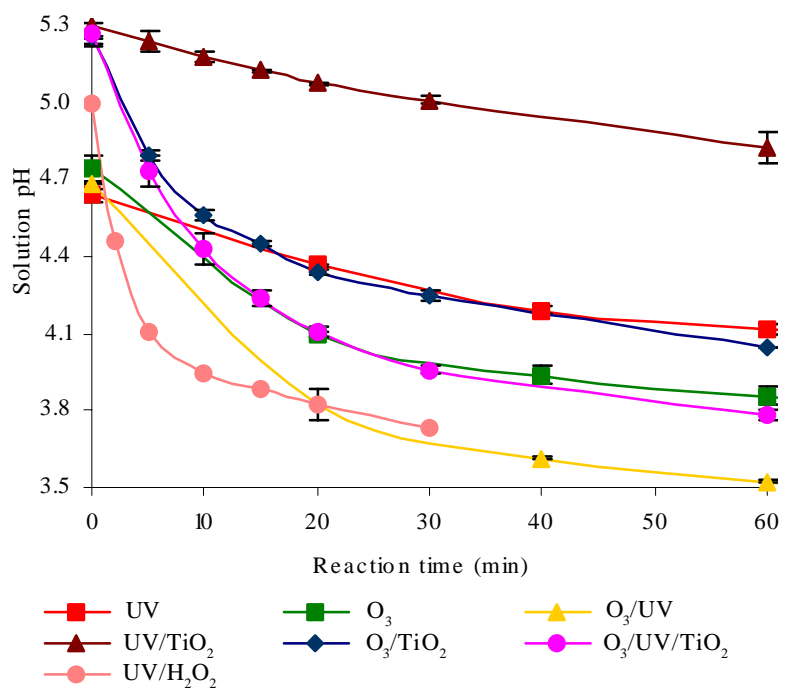

Fig. 1: Variation in solution $\mathrm{pH}$ during oxidaiton of pharmaceutical compounds as an indication of the extent of PPCPs degradation. The values dropped sharply (1.48) within $60 \mathrm{~min}$ with $\mathrm{O}_{3} / \mathrm{UV} / \mathrm{TiO}_{2}$, while $\mathrm{O}_{3} / \mathrm{TiO}_{2}$ was in the second place (1.21) among the three $\mathrm{TiO}_{2}$-catalyzed methods during the same time interval. $\mathrm{O}_{3} / \mathrm{UV}, \mathrm{O}_{3} / \mathrm{TiO}_{2}$ and $\mathrm{O}_{3}$ were in decreasing order in terms of $\mathrm{pH}$ drop among the tested methods excluding $\mathrm{UV} / \mathrm{H}_{2} \mathrm{O}_{2}$. Slightly larger initial $\mathrm{pH}$ values with $\mathrm{UV} / \mathrm{H}_{2} \mathrm{O}_{-2}$ may be attributed to $\mathrm{H}_{2} \mathrm{O}_{2}$, while photolysis of $\mathrm{H}_{2} \mathrm{O}_{2}$ also might have contributed to relatively larger $\mathrm{pH}$ drop within $30 \mathrm{~min}$ (1.27).

\section{Dissolved residual ozone}

Dissolution of gas phase ozone in aqueous solution is the first step for oxidation of organics by the methods involving ozonation. Measurement of dissolved residual ozone may be helpful to get better insight of PPCPs degradation. Aqueous phase ozone profiles (Fig. 2) for the four methods involving ozonation exhibited the largest ozone concentrations with $\mathrm{O}_{3} / \mathrm{UV}$, followed by $\mathrm{O}_{3}$. Very smaller ozone concentrations were observed with $\mathrm{O}_{3} / \mathrm{TiO}_{2}$ and $\mathrm{O}_{3} / \mathrm{UV} / \mathrm{TiO}_{2}$ compared to those of $\mathrm{O}_{3}$ and $\mathrm{O}_{3} / \mathrm{UV}$. It is argued that dissolved ozone is first adsorbed onto $\mathrm{TiO}_{2}$ surface (Beltran et al., 2005) in $\mathrm{TiO}_{2}$-catalyzed ozonation resulting in its reduced aqueous concentrations compared to those in ozonation. Ozone photolysis is a well-documented phenomenon ultimately resulting to formation of very powerful hydroxyl radical ( $\left.{ }^{\circ} \mathrm{OH}\right)$ in $\mathrm{O}_{3} / \mathrm{UV}$. It appeared from the concentration profiles (Fig. 2) that ozone dissolution also might be enhanced in presence of UV

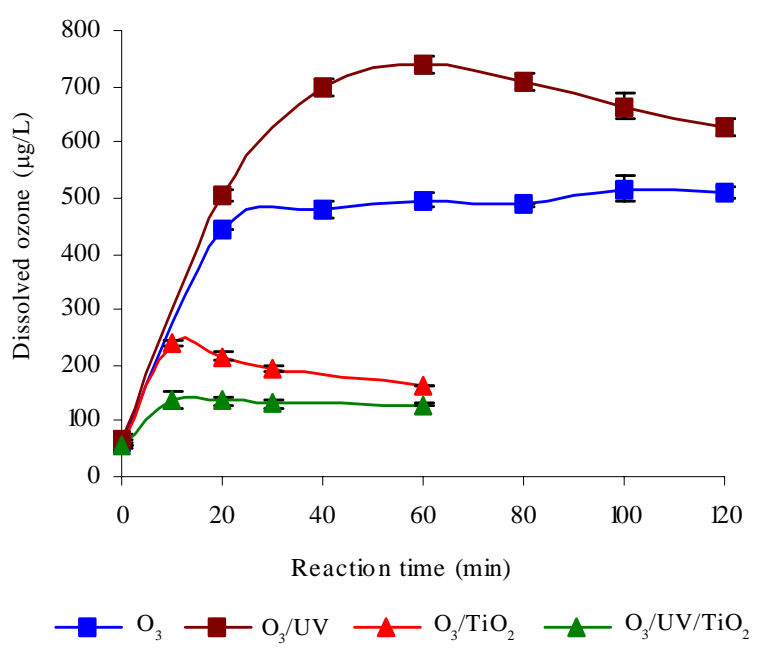

Fig. 2: Variation in dissolved ozone during oxidation of pharmaceuticals by $\mathrm{O}_{3}, \mathrm{O}_{3} / \mathrm{UV}, \mathrm{O}_{3} / \mathrm{TiO}_{2}$ and $\mathrm{O}_{3} / \mathrm{UV} / \mathrm{TiO}_{2}$ 

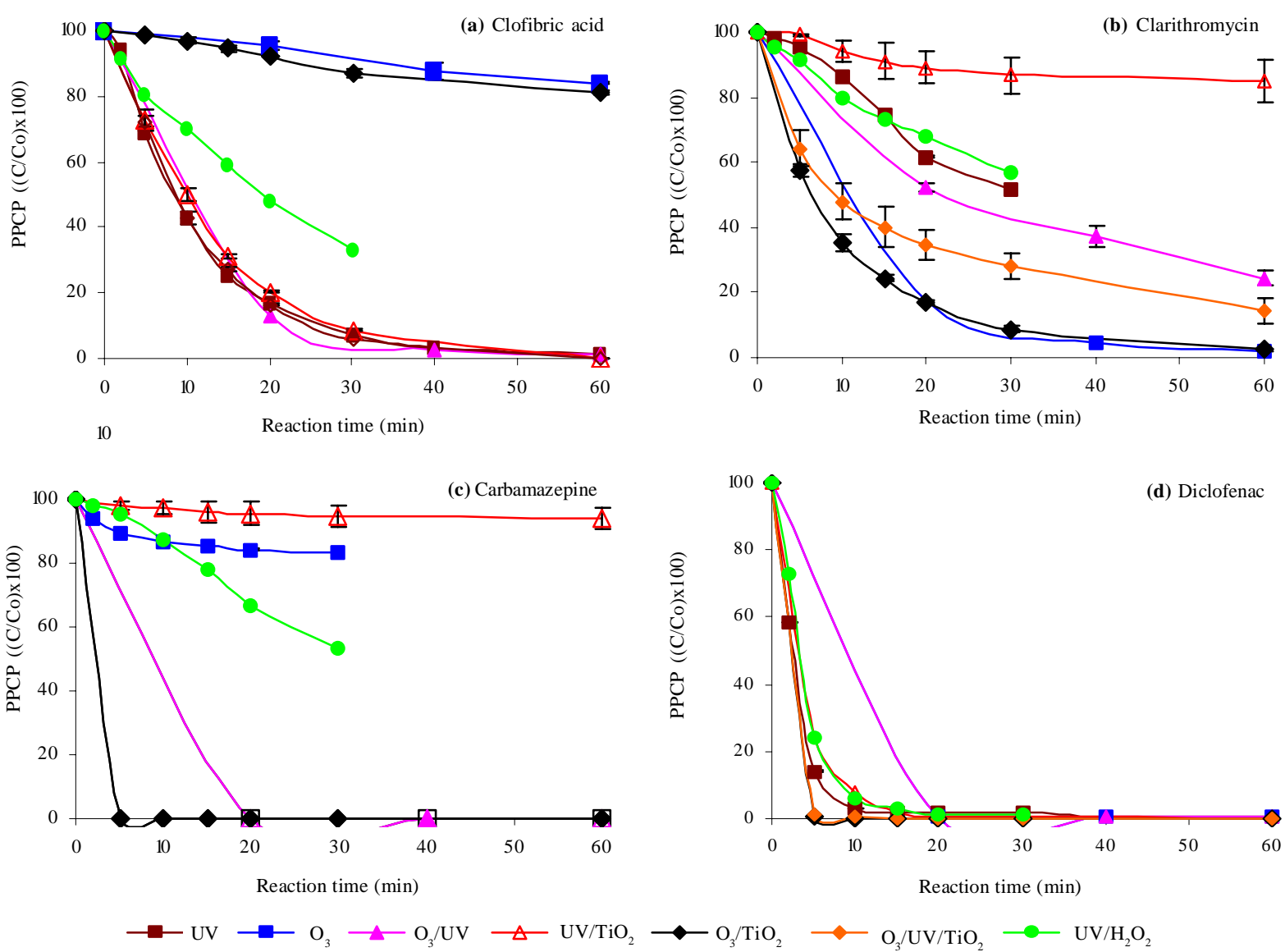

Fig. 3 Relative concentration profiles for clofibric acid, clarithromycin, carbamazepine and diclofenac

irradiation. The process of ozone adsorption onto $\mathrm{TiO}_{2}$ surface and its subsequent decomposition leading to ${ }^{2}$ $\mathrm{OH}$ formation is significantly enhanced in UV-assisted $\mathrm{TiO}_{2}$-catalyzed ozonation $\left(\mathrm{O}_{3} / \mathrm{UV} / \mathrm{TiO}_{2}\right)$ (Beltran et al., 2005; El-Diwani and El-Rafie, 2008; Gharbani et al., 2008). Thus, the very small ozone concentrations with $\mathrm{O}_{3} / \mathrm{TiO}_{2}$ may be attributed to its adsorption onto $\mathrm{TiO}_{2}$ surface, while both adsorption onto $\mathrm{TiO}_{2}$ surface and enhanced decomposition in presence of UV might have resulted to further smaller ozone concentrations with $\mathrm{O}_{3} / \mathrm{UV} / \mathrm{TiO}_{2}$.

\section{Removal performance}

Inconsistency in initial concentration of particularly TCC was observed throughout the investigation. Small initial TCC concentrations with $\mathrm{UV}, \mathrm{UV} / \mathrm{TiO}_{2}, \mathrm{O}_{3}$ and $\mathrm{O}_{3} /$ UV were attributed to its very small water solubility (0.0237 mg/L). However, reason behind its very high concentrations with $\mathrm{O}_{3} / \mathrm{TiO}_{2}$ and $\mathrm{O}_{3} / \mathrm{UV} / \mathrm{TiO}_{2}$ was not known. Slightly smaller initial CAM concentrations observed in this investigation may also be associated to small water solubility value $(0.342 \mathrm{mg} / \mathrm{L})$ of the compound. Smaller initial TCS concentrations with $\mathrm{TiO}_{2}$ catalyzed methods were possibly due to its adsorption onto $\mathrm{TiO}_{2}$.

$\mathrm{O}_{3}$ and $\mathrm{O}_{3} / \mathrm{TiO}_{2}$ were inefficient to degrade CA (Fig. $3 a)$, which is consistent with an earlier report (Ikehata et al., 2006), while other methods (except $\mathrm{UV} / \mathrm{H}_{2} \mathrm{O}_{2}$ ) exhibited greatly enhanced, but similar removals of the compound. Thus, UV-based methods exhibited better CA removals than ozone-based methods. The inefficiency of $\mathrm{O}_{3}$-based methods to degrade CA may be attributed to relatively smaller initial solution $\mathrm{pH}$ values (Ikehata et al., 2006). UV alone was more efficient than $\mathrm{UV} / \mathrm{TiO}_{2}$ to degrade CAM (Fig. 3b), while no significant difference on its degradation by UV and $\mathrm{UV} / \mathrm{H}_{2} \mathrm{O}_{2}$ was observed. Unlike with $\mathrm{CA}, \mathrm{O}_{3}$ and $\mathrm{O}_{3} /$ $\mathrm{TiO}_{2}$ appeared to be the most efficient methods for 

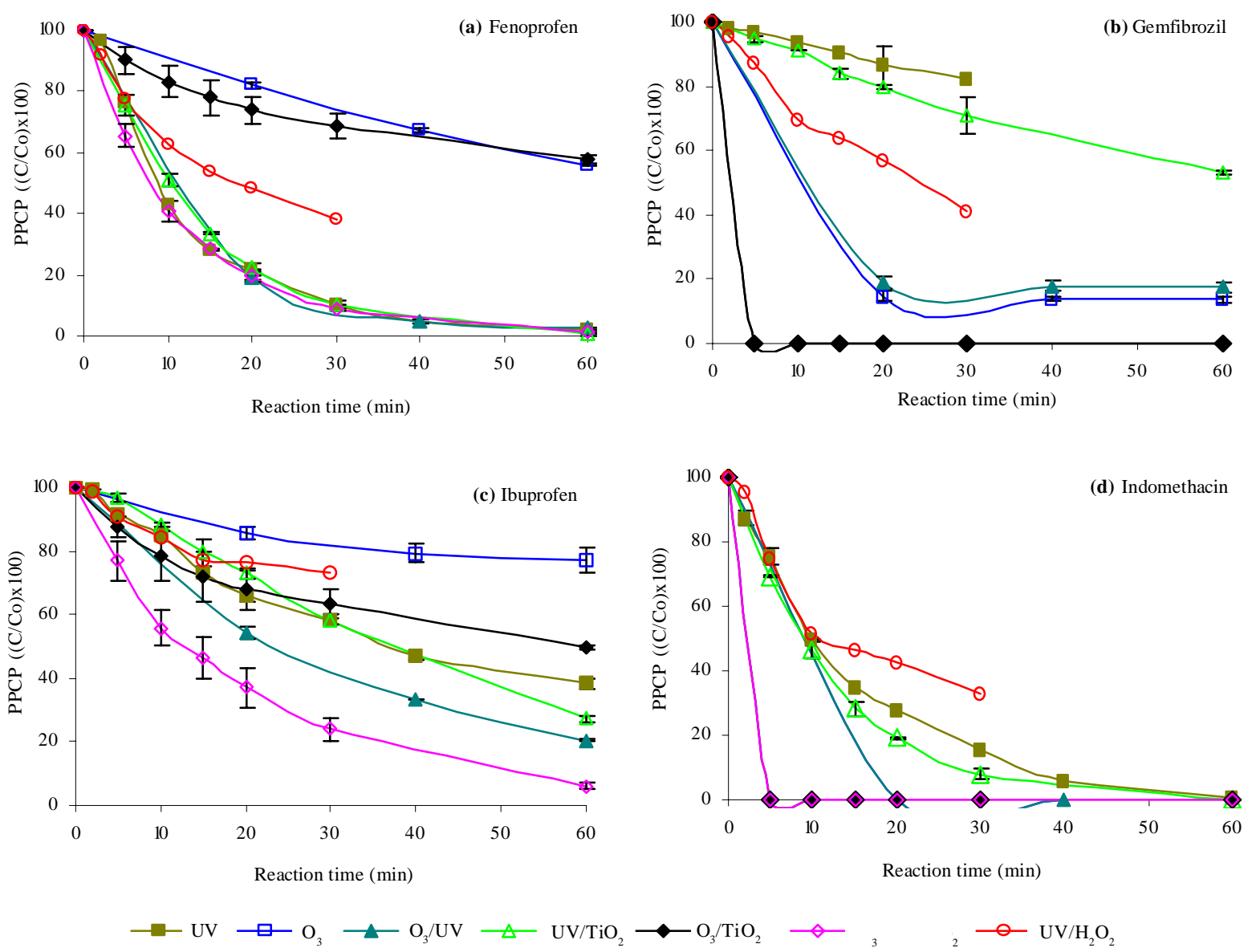

Fig. 4: Relative concentration profiles for fenoprofen, gemfibrozil, ibuprofen and indomethacin

CAM degradation. Moreover, its degradations by $\mathrm{O}_{3} /$ UV drastically decreased compared to those by ozonation alone. But the negative impact of $\mathrm{UV}$ in $\mathrm{O}_{3} /$ UV process was significantly reduced in presence of $\mathrm{TiO}_{2}$ (i.e. $\mathrm{O}_{3} / \mathrm{UV} / \mathrm{TiO}_{2}$ ). Therefore, ozone-based methods appeared to be more suitable than UV-based methods for CAM removal. An earlier report also mentioned ozonation as a suitable method for its efficient removal (Lange et al., 2006). Similar with CAM, UV-based methods were inefficient to degrade CBZ (Fig. 3c). UV/ $\mathrm{H}_{2} \mathrm{O}_{2}$ appeared to be relatively better than UV alone while $\mathrm{UV} / \mathrm{TiO}_{2}$ was the most inefficient method. Contrary to an earlier report (Ikehata et al., 2006), UV/ $\mathrm{TiO}_{2}$ and $\mathrm{UV} / \mathrm{H}_{2} \mathrm{O}_{2}$ were found to be very inefficient than $\mathrm{O}_{3}$ to degrade CBZ. Ozone-based methods degraded CBZ more efficiently than CAM due to high reactivity of CBZ with ozone (Ikehata et al., 2006). DCF was degraded very efficiently within short reaction periods irrespective of the employed oxidation methods
(Fig. 3d). Its efficient degradation by $\mathrm{O}_{3}$ and $\mathrm{UV} / \mathrm{H}_{2} \mathrm{O}_{2}$ is reported earlier (Vonga et al., 2004). Oxidation of FEP (Fig. 4a) was similar to that of $\mathrm{CA} . \mathrm{O}_{3}$ and $\mathrm{O}_{3} / \mathrm{TiO}_{2}$ were not very effective, while other methods excluding UV/ $\mathrm{H}_{2} \mathrm{O}_{2}$ degraded the compound very efficiently. The reduced FEP degradation by $\mathrm{UV} / \mathrm{H}_{2} \mathrm{O}_{2}$ compared to those by other UV-based methods may be attributed to UV scavenging by $\mathrm{H}_{2} \mathrm{O}_{2}$ resulting in reduced quantum yield. Thus, UV-based methods were superior to ozone-based methods to remove the compound. To the contrary, ozone-based methods rather than UVbased methods degraded GFZ very efficiently (Fig. 4b). $\mathrm{O}_{3}$ and $\mathrm{O}_{3} / \mathrm{UV}$ appeared not to be very useful to degrade GFZ at low concentrations, while the compound was very efficiently removed in presence of both $\mathrm{O}_{3}$ and $\mathrm{TiO}_{2}$ (e.g. $\mathrm{O}_{3} / \mathrm{TiO}_{3}$ and $\mathrm{O}_{3} / \mathrm{UV} / \mathrm{TiO}_{2}$ ). The compound was degraded by $\mathrm{UV} / \mathrm{TiO}{ }_{2}$ relatively faster than that by UV alone, while the degradation was further enhanced in case of $\mathrm{UV} / \mathrm{H}_{2} \mathrm{O}_{2}$ possibly due to $\mathrm{OH}$ 
R. R. Giri et al.
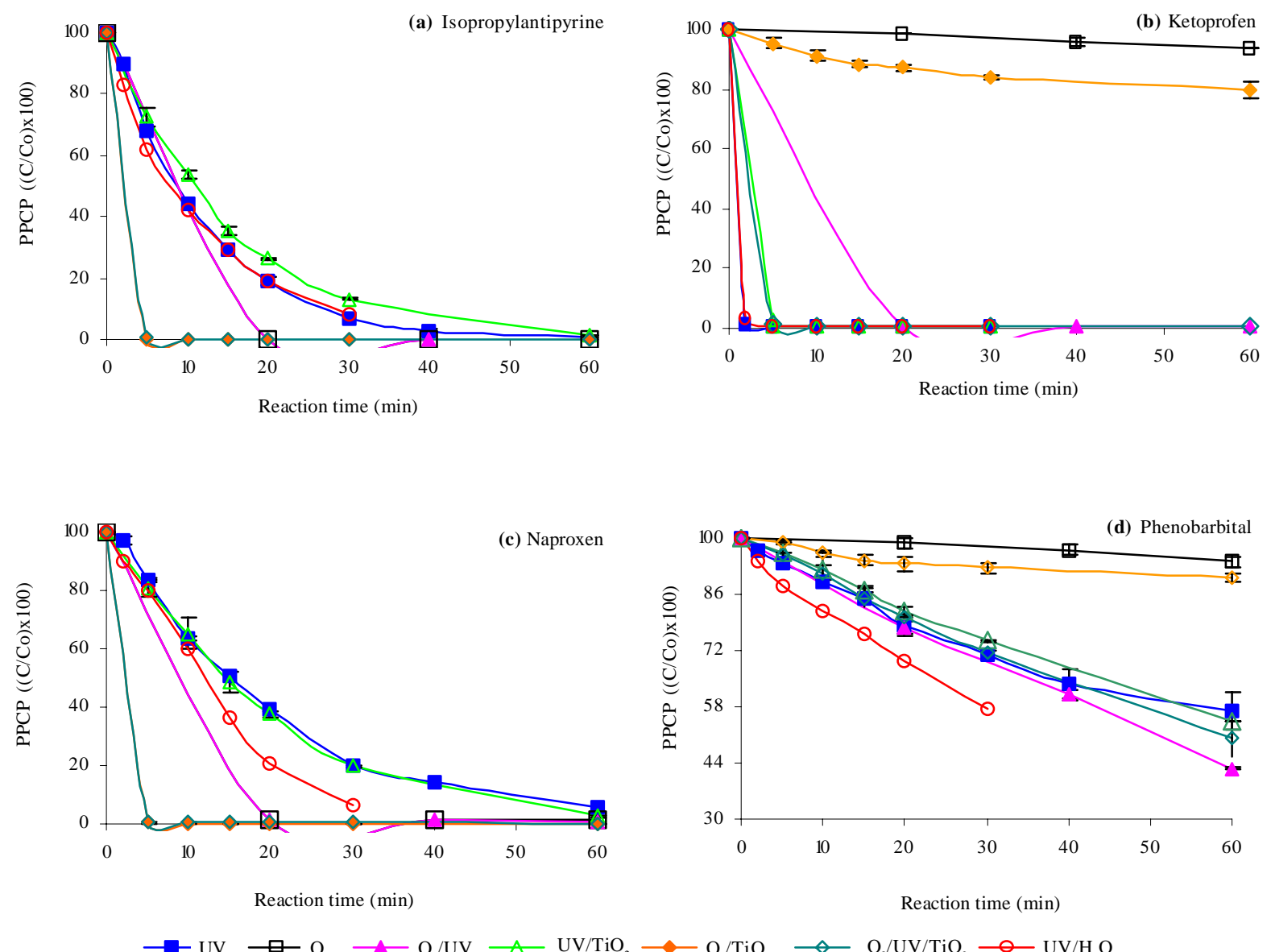

Fig. 5: Relative concentration profiles for isopropylantipyrine, ketoprofen, naproxen and phenobarbital

Table 1: Apparent first-order removal rate values $\left(\mathrm{h}^{-1}\right)$ for PPCPs

\begin{tabular}{|c|c|c|c|c|c|c|c|}
\hline \multirow{2}{*}{ PPCPs } & \multicolumn{7}{|c|}{ Oxidation methods } \\
\hline & UV & $\mathrm{UV} / \mathrm{TiO}_{2}$ & $\mathrm{UV} / \mathrm{H}_{2} \mathrm{O}_{2}$ & $\mathrm{O}_{3}$ & $\mathrm{O}_{3} / \mathrm{UV}$ & $\mathrm{O}_{3} / \mathrm{TiO}_{2}$ & $\mathrm{O}_{3} / \mathrm{UV} / \mathrm{TiO}_{2}$ \\
\hline CA & 5.38 & 4.98 & 2.18 & 0.16 & 6.80 & 0.28 & 5.83 \\
\hline CAM & 1.42 & 0.32 & 1.13 & 5.86 & 1.85 & 4.82 & 1.75 \\
\hline CBZ & 1.30 & 0.13 & 1.30 & 64.20 & 158.47 & 118.33 & NA \\
\hline DCF & 17.02 & 16.00 & 14.93 & 108.33 & 70.47 & 71.33 & 56.47 \\
\hline FEP & 4.82 & 4.85 & 2.54 & 0.49 & 5.05 & 0.74 & 4.52 \\
\hline GFZ & 0.40 & 0.64 & 1.76 & 40.79 & 63.37 & 121.06 & NA \\
\hline IBP & 1.28 & 1.33 & 1.07 & 0.31 & 1.76 & 1.19 & 2.75 \\
\hline IDM & 3.78 & 5.11 & 3.36 & 73.86 & 95.90 & 120.48 & NA \\
\hline IPA & 5.29 & 4.37 & 4.91 & NA & 197.39 & 113.88 & 64.97 \\
\hline KEP & 58.47 & 31.09 & 62.39 & 1.02 & 96.72 & 0.42 & 53.78 \\
\hline NPX & 3.24 & 3.73 & 4.51 & 85.35 & 61.49 & 65.75 & 55.81 \\
\hline PB & 0.68 & 0.62 & 1.06 & 0.88 & 0.97 & 0.24 & 0.71 \\
\hline PNC & 0.26 & 0.15 & 0.28 & 1.85 & 0.57 & 10.94 & 1.36 \\
\hline PNT & 3.34 & 2.65 & 2.97 & 0.20 & 4.19 & 0.10 & 3.65 \\
\hline TCC & 9.75 & 1.52 & 1.93 & 2.10 & 3.91 & 2.41 & 2.89 \\
\hline TCS & 12.82 & NA & 8.12 & NA & NA & NA & NA \\
\hline
\end{tabular}

NA: Not available 

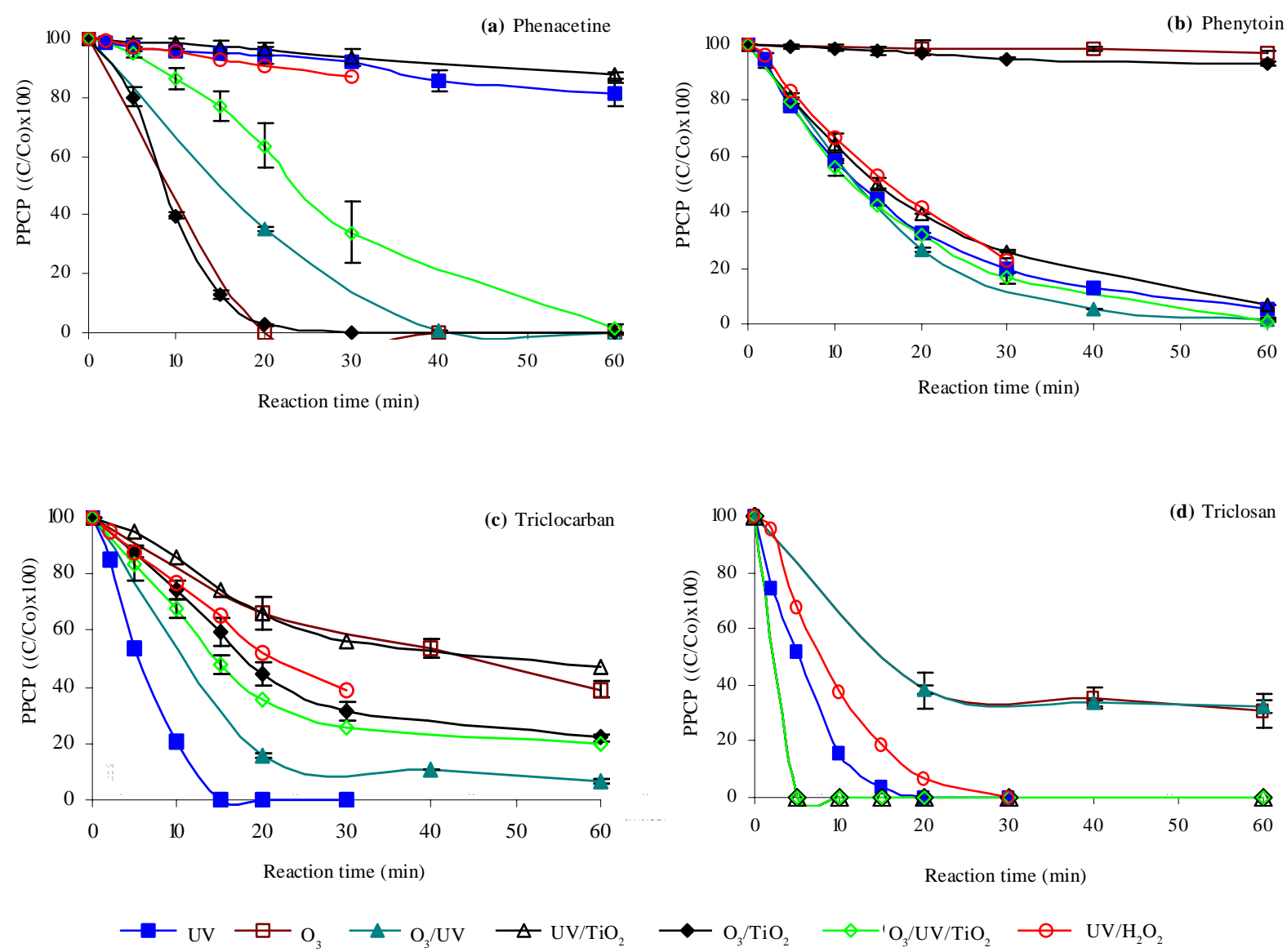

Fig. 6: Relative concentration profiles for phenacetine, phenytoin, triclocarban and triclosan

formation. IBP was relatively more resistant to degradations than the PPCPs discussed so far (Fig. 4c). Similar with CA, ozonation alone could not degrade IBP considerably, which is consistent to an earlier report (Ikehata et al., 2006). But, Snyder et al. (2006) reported over $80 \%$ removals of the compound by ozonation alone in bench and pilot-scale experiments. UV alone was more powerful than $\mathrm{O}_{3}$, but no clear differences were observed among $\mathrm{UV}, \mathrm{UV} / \mathrm{TiO}_{2}$ and UV/ $\mathrm{H}_{2} \mathrm{O}_{2}$ with respect to IBP removals. $\mathrm{O}_{3} / \mathrm{UV}$ appeared to be better than other methods excluding $\mathrm{O}_{3} / \mathrm{UV} / \mathrm{TiO}_{2}$, while the latter exhibited the best performance for IBP removal. IDM was easily degraded by all the methods investigated (Fig. 4d). But $\mathrm{O}_{3}$ and $\mathrm{O}_{3}$-based methods appeared relatively better than UV-based methods. But, only a few investigations are reported on advanced oxidation of IDM (Ikehata et al., 2006).

Similar to IDM, all the seven AOPs very efficiently degraded IPA (Fig. 5a). But KEP(Fig. 5b) behaved very differently with UV-based methods and $\mathrm{O}_{3}$-based methods. $\mathrm{O}_{3}$-based methods were of no use to degrade KEP, while UV-based methods degraded the compound within short reaction periods. Similar to DCF, IPA and IDM, NPX (Fig. 5c) was effectively degraded by all the methods investigated. But $\mathrm{O}_{3}$-based methods appeared relatively better than UV-based methods. PB (Fig. 5d) was more resistant to degradations than IBP discussed in earlier paragraph. $\mathrm{O}_{3}$ and $\mathrm{O}_{3} / \mathrm{TiO}_{2}$ were not useful at all to degrade the compound, while degradation profiles for other methods excluding $\mathrm{UV} / \mathrm{H}_{2} \mathrm{O}_{2}$ were similar. UV/ $\mathrm{H}_{2} \mathrm{O}_{2}$ exhibited better $\mathrm{PB}$ removal performance than $\mathrm{UV} /$ $\mathrm{TiO}_{2}, \mathrm{O}_{3} / \mathrm{UV}$ and $\mathrm{O}_{3} / \mathrm{UV} / \mathrm{TiO}_{2}$.

Similar to CAM, CBZ and GFZ, UV-based methods ( $\mathrm{UV}, \mathrm{UV} / \mathrm{TiO}_{2}$ and $\mathrm{UV} / \mathrm{H}_{2} \mathrm{O}_{2}$ ) were not useful at all to degrade $\mathrm{PNC}$, but $\mathrm{O}_{3}$ and $\mathrm{O}_{3}$-based methods were very powerful to degrade the compound (Fig. 6a). $\mathrm{O}_{3}$ and $\mathrm{O}_{3} / \mathrm{TiO}_{2}$ were similar in terms of PNC removals. The 
decreased PNC removals by $\mathrm{O}_{3} / \mathrm{UV}$ and $\mathrm{O}_{3} / \mathrm{UV} / \mathrm{TiO}_{2}$ may be attributed to ozone scavenging by $\mathrm{UV}$ and $\mathrm{TiO}_{2}$. PNT (Fig. 6b) exhibited similar behaviors to those of $\mathrm{CA}$ and $\mathrm{PB}$ with respect to its removals. $\mathrm{O}_{3}$ and $\mathrm{O}_{3} / \mathrm{TiO}_{2}$ were not useful at all to degrade the compound, while other methods were very efficient with similar removal profiles. As mentioned earlier, very large differences in initial TCC concentrations were observed that might have significantly influenced its degradations. UV was the most effective method to degrade TCC, while $\mathrm{O}_{3}$-based methods $\left(\mathrm{O}_{3}, \mathrm{O}_{3} / \mathrm{TiO}_{2}\right.$ and $\left.\mathrm{O}_{3} / \mathrm{UV} / \mathrm{TiO}_{2}\right)$ were less efficient than $\mathrm{UV}^{3}$ and $\mathrm{O}_{3} / \mathrm{UV}$ (Fig. 6c). UV scavenging by $\mathrm{H}_{2} \mathrm{O}_{2}$ and $\mathrm{TiO}_{2}$ may have resulted to the greatly reduced TCC removals by $\mathrm{UV} / \mathrm{H}_{2} \mathrm{O}_{2}$ and $\mathrm{UV} / \mathrm{TiO}_{2}$, respectively. TCS quickly disappeared with the methods involving $\mathrm{TiO}_{2}$ fiber presumably due to its adsorption to the catalyst (Fig. 6d). UV was the most efficient method to degrade TCS, while UV/ $\mathrm{H}_{2} \mathrm{O}_{2}$ followed $\mathrm{UV} . \mathrm{O}_{3}$ and $\mathrm{O}_{3} / \mathrm{UV}$ appeared not being efficient to degrade the compound at low concentrations, which is contrary to an earlier report (Snyder et al., 2006) that presented over $80 \%$ TCS removals by ozonation.

Based on the removal profiles discussed so far, the sixteen compounds can be roughly grouped into four categories. DCF, IDM, IPA, NPX and TCS were easily degraded by all the seven tested AOPs. But, IBP and $\mathrm{PB}$ were relatively difficult to degrade by all the AOPs. CA, FEP, KEP, PNT and TCC were easily degraded by $\mathrm{UV}$ and UV-based methods, but $\mathrm{O}_{3}$ and $\mathrm{O}_{3}$-based methods were of no use for their removal. On the other hand, CAM, CBZ, GFZ and PNC were easily degraded by $\mathrm{O}_{3}$ and $\mathrm{O}_{3}$-based methods, but UV and UV-based methods were not effective at all for their removal.

\section{Degradation kinetic and rate values}

A separate set of experiments with 20 min reaction period were conducted for degradation kinetic analysis of the compounds in mixed solutions using the AOPs. The degradations were well described by the firstorder reaction kinetic $\left(\mathrm{R}^{2} \geq 0.98\right)$, which is consistent to an earlier report (Kim et al., 2008). The apparent firstorder degradation rate $(\mathrm{k})$ values are shown in Table 1.

The k values for PNC and TCC with $\mathrm{O}_{3} / \mathrm{TiO}_{2}$ and UV respectively were at least 6 -folds and 2.5 -folds larger than the values with other methods. The k values for CAM with $\mathrm{O}_{3} / \mathrm{TiO}_{2}$ and $\mathrm{O}_{3}$, respectively were at least 2.6 and 3.2-folds larger than the values with remaining methods. Therefore, $\mathrm{O}_{3} / \mathrm{TiO}_{2}$ and $\mathrm{O}_{3}$, respectively could be the methods of choice for efficient oxidations of the compounds. Small k value with UV and significant reduction in the value for $\mathrm{CAM}$ with $\mathrm{O}_{3} / \mathrm{UV}$ compared to that with $\mathrm{O}_{3}$ were consistent to an earlier reported result (Kim et al., 2008). However, the values with UV and $\mathrm{UV} / \mathrm{H}_{2} \mathrm{O}_{2}$ were closer unlike in the earlier report. Similarly, $\mathrm{k}$ values for CA and PNT with $\mathrm{O}_{3} / \mathrm{UV}$ were at least 1.1 to 1.2 -folds larger than those with other methods. The $\mathrm{k}$ values for FEP with $\mathrm{O}_{3}$ and $\mathrm{O}_{3} / \mathrm{TiO}_{2}$ were about 6.5-folds smaller than those with other methods excluding $\mathrm{UV} / \mathrm{H}_{2} \mathrm{O}_{2}$. Unlike an earlier report (Kim et al., 2008), rate value for the compound with $\mathrm{UV} / \mathrm{H}_{2} \mathrm{O}_{2}$ was about half of the value with UV. Very small $\mathrm{k}$ values for PB (0.24 1.06/h) and IBP (0.31 $2.75 / \mathrm{h}$ ) with all the investigated AOPs once again indicated recalcitrant nature of the two compounds for oxidation.

The $\mathrm{k}$ values for IPA with $\mathrm{O}_{3} / \mathrm{UV}, \mathrm{O}_{3} / \mathrm{TiO}_{2}$ and $\mathrm{O}_{3} /$ $\mathrm{UV} / \mathrm{TiO}_{2}$ were respectively about 39,23 and 13 -folds larger than those with other methods excluding $\mathrm{O}_{3}$. IPA with $\mathrm{O}_{3}$ disappeared within a very short period and hence $\mathrm{k}$ value could not be evaluated. The decreasing $\mathrm{k}$-values of IPA with $\mathrm{O}_{3} / \mathrm{UV}, \mathrm{O}_{3} / \mathrm{TiO}_{2}$ showed that direct ozone reaction was presumably the most powerful oxidation method for the compound. The value with $\mathrm{O}_{3} / \mathrm{UV}$ in this investigation was about 4-folds larger than reported in Kim et al. (2008). The k values for CBZ with $\mathrm{O}_{3} / \mathrm{UV}, \mathrm{O}_{3} / \mathrm{TiO}_{2}$ and $\mathrm{O}_{3}$ were about 122, 91 and 49folds larger than those with the remaining AOPs excluding $\mathrm{O}_{3} / \mathrm{UV} / \mathrm{TiO}_{2}$. The $\mathrm{k}$ value with $\mathrm{O}_{3} / \mathrm{UV}$ in this investigation was about 9-folds larger than reported in Kim et al. (2008). Very quick disappearance of the compound with $\mathrm{O}_{3} / \mathrm{UV} / \mathrm{TiO}_{2}$ indicated its larger $\mathrm{k}$ value than with $\mathrm{O}_{3} / \mathrm{UV}$.

The $\mathrm{k}$ values for IDM and GFZ with $\mathrm{O}_{3}, \mathrm{O}_{3} / \mathrm{UV}$ and $\mathrm{O}_{3} / \mathrm{TiO}_{2}$ were respectively about $15,19,24$ and 23,36 , 69 -folds larger than those for other AOPs excluding $\mathrm{O}_{3} / \mathrm{UV} / \mathrm{TiO}_{2}$. The $\mathrm{k}$ value for IDM with $\mathrm{O}_{3} / \mathrm{UV}$ in this investigation was about 2-folds larger than reported in Kim et al. (2008). Similar to CBZ, IDM and GFZ disappeared very quickly with $\mathrm{O}_{3} / \mathrm{UV} / \mathrm{TiO}_{2}$ indicating larger $\mathrm{k}$ values of the compounds with the method. Unlike for IPA, the significantly increasing $\mathrm{k}$ values for IDM and GFZ with $\mathrm{O}_{3} / \mathrm{UV}, \mathrm{O}_{3} / \mathrm{TiO}_{2}$ and $\mathrm{O}_{3} / \mathrm{UV} / \mathrm{TiO}_{2}$ may be explained on the basis of enhanced ozone dissolution and decomposition in presence of UV and $\mathrm{TiO}_{2}$ (Beltran et al., 2005). But this explanation appeared not to be always applicable to all the tested PPCPs in this investigation. The rate values for NPX and DCF successively decreased with $\mathrm{O}_{3}, \mathrm{O}_{3} / \mathrm{TiO}_{2}, \mathrm{O}_{3} / \mathrm{UV}$ and 
$\mathrm{O}_{3} / \mathrm{UV} / \mathrm{TiO}_{2}$, while Kim et al. (2008) reported largest $\mathrm{k}$ values of the compounds with $\mathrm{O}_{3} / \mathrm{UV}$. The value for $\mathrm{NPX}$ with $\mathrm{O}_{3}$ was 1.3, 1.4 and 1.5-folds larger than those of $\mathrm{O}_{3} / \mathrm{TiO}_{2}, \mathrm{O}_{3} / \mathrm{UV}$ and $\mathrm{O}_{3} / \mathrm{UV} / \mathrm{TiO}_{2}$, respectively. Similarly, k value for DCF was respectively 1.5, 1.5 and 1.9-folds larger. It is apparent from this observation that increased dissolution and decomposition of ozone in ozone-based oxidation methods may not enhance degradations of all organic compounds.

The $\mathrm{k}$ value for TCS with UV was about 1.6-fold larger than that with $\mathrm{UV} / \mathrm{H}_{2} \mathrm{O}_{2}$. KEP exhibited different behaviors with the AOPs in terms of its $\mathrm{k}$ values. The $\mathrm{k}$ values for $\mathrm{KEP}$ with $\mathrm{UV} / \mathrm{TiO}_{2}, \mathrm{UV} / \mathrm{H}_{2} \mathrm{O}_{2}, \mathrm{O}_{3} / \mathrm{UV}$ and $\mathrm{O}_{3} /$ $\mathrm{UV} / \mathrm{TiO}_{2}$ were respectively about $0.5,1.1,1.6$ and 0.9 folds of the value with UV, while the values with the remaining two AOPs were negligibly small. Therefore, $\mathrm{O}_{3} / \mathrm{UV}$ was the most appropriate method for KEP removal. Unlike with other compounds, $\mathrm{k}$ value for KEP with $\mathrm{O}_{3} / \mathrm{UV}$ in this investigation was about 2.5-fold smaller than the value reported in Kim et al. (2008). Moreover, k values for majority of the compounds with $\mathrm{UV} / \mathrm{H}_{2} \mathrm{O}_{2}$ were similar to and/or smaller than the corresponding values with UV, which is contrary to the cases reported in Kim et al. (2008). The largest $\mathrm{k}$ values for TCC and TCS were observed with UV. PB and IBP respectively showed the largest $k$ values with $\mathrm{UV} / \mathrm{H}_{2} \mathrm{O}_{2}$ and $\mathrm{O}_{3} / \mathrm{UV} / \mathrm{TiO}_{2}$. Similarly, the largest $\mathrm{k}$ values for DCF, NPX, CAM and IDM, GFZ, PNC were observed with $\mathrm{O}_{3}$ and $\mathrm{O}_{3} / \mathrm{TiO}_{2}$ respectively. CA, CBZ, FEP, IPA, KEP and PNT exhibited the largest $k$ values with $\mathrm{O}_{3} /$ UV (Table 1). Similarly, CAM, DCF, NPX and GFZ, IDM, PNC showed the largest $\mathrm{k}$ values with $\mathrm{O}_{3}$ and $\mathrm{O}_{3} / \mathrm{TiO}_{2}$ respectively. Only two compounds (TCC and TSC) had the largest $k$ values with UV, only PB and IBP showed the largest $\mathrm{k}$ values with $\mathrm{UV} / \mathrm{H}_{2} \mathrm{O}_{2}$ and $\mathrm{O}_{3} / \mathrm{UV} / \mathrm{TiO}_{2}$ respectively, while any of the compounds did not exhibit the largest $\mathrm{k}$ value with $\mathrm{UV} / \mathrm{TiO}_{2}$. Based on the $\mathrm{k}$ values (Table 1 ), $\mathrm{O}_{3} / \mathrm{UV}$ removed simultaneously the largest number of PPCPs (twelve) efficiently among the tested AOPs, while the numbers for $\mathrm{O}_{3} / \mathrm{UV} / \mathrm{TiO}_{2}$, $\mathrm{O}_{3} / \mathrm{TiO}_{2}$ and $\mathrm{O}_{3}$ are ten, nine and six respectively.

Relatively larger solution $\mathrm{pH}$ values with $\mathrm{UV} / \mathrm{TiO}_{2}$ might have negatively affected its performance to some extent in this investigation. Addition of $\mathrm{H}_{2} \mathrm{O}_{2}$ in $\mathrm{UV}$ photodegradation was not worthy, which is consistent to an earlier report (Baumgarten et al., 2007). Since increased ozone dissolution and decomposition alone did not fully explain degradations of PPCPs by $\mathrm{TiO}_{2}$ catalyzed methods, physicochemical characteristics of the compounds too presumably played an important role on their removal. It is apparent from the results that $\mathrm{O}_{3}$-based methods rather than UV-based methods were very efficient to remove a large number of the compounds simultaneously in mixed solutions, which is consistent to earlier reports (Jasim et al., 2006; Snyder et al., 2006; Baumgarten et al., 2007; Kim et al., 2008). Furthermore, $\mathrm{O}_{3} / \mathrm{UV}$ was the most appropriate method among the tested $\mathrm{O}_{2}$-based AOPs based on removal profiles and $\mathrm{k}$ values for the compounds.

\section{CONCLUSION}

Removal profiles of sixteen pharmaceutical compounds with seven AOPs demonstrated four distinct patterns. DCF, IDM, IPA, NPX and TCS were easily removed, while IBP and $\mathrm{PB}$ were very resistant to degradation by all AOPs. UV-based AOPs efficiently removed CA, FEP, KEP, PNT and TCC, but $\mathrm{O}_{3}$-based AOPs were of no use. Similarly, $\mathrm{O}_{3}$-based AOPs were very efficient to eliminate CAM, CBZ, GFZ and PNC, while UV-based AOPs were not useful at all. Ozonebased AOPs rather than UV-based AOPs were very efficient to simultaneously remove a large number of the compounds based on the first-order removal rate values. Both removal profiles and rate values demonstrated $\mathrm{O}_{3} / \mathrm{UV}$ as the most appropriate AOP for simultaneous removal of the tested compounds very efficiently in mixed solution. Increased ozone dissolution and decomposition with $\mathrm{O}_{3}$-based AOPs did not always enhance removal of the tested compounds. Solution $\mathrm{pH}$ and physicochemical characteristics of the compounds also presumably played an important role on the removal, which merits further attention.

\section{REFERENCES}

Baumgarten, S.; Schroder, H. F.; Charwath, C.; Lange, M.; Beier, S.; Pinnekamp, J. (2007). Evaluation of advanced treatment technologies for the elimination of pharmaceutical compounds. Water Sci. Tech., 56 (5), 1-8 (8 pages).

Beltran, F. J.; Rivas, F. J.; Gimeno, O., (2005). Comparison between photocatalytic ozonation and other oxidation processes for the removal of phenols from water. J. Chem. Tech. Biotech., 80 (9), 973-984 (12 pages).

Calza, P.; Sakkas, V. A.; Medana, C.; Baiochhi, C.; Dimou, A.; Pelizzetti, E.; Albanis, T., (2006). Photocatalytic degradation study of diclofenac over aqueous $\mathrm{TiO}_{2}$ suspensions. Appl. Catal. B, 67 (3-4), 197-205 (9 pages).

Canonica, S.; Meunier, S. L.; Gunten, U. V., (2008). Phototransformation of selected pharmaceuticals during UV treatment of drinking water. Water Res., 42 (1-2), 121-128 (8 pages). 
Dalrymple, O. K.; Yeh, D. H.; Trotz, M. A., (2007). Removing pharmaceuticals and endocrine-disrupting compounds from wastewater by photocatalysis: A review. J. Chem. Tech. Biotech., 82 (2), 121-134 (14 pages).

Das, P.; Pal, R.; Chowdhury, A., (2008). Influence of bioticabiotic factors on the degradation of novaluron in tropical soil. Int. J. Environ. Sci. Tech., 5 (3), 425-429 (5 pages).

Doll, T. E.; Frimmel, F. H. (2005). Photocatalytic degradation of carbamazepine, clofibric acid and iomeprol with P25 and Hombikat UV100 in the presence of natural organic matter (NOM) and other organic water constituents. Water Res., 39 (2-3), 403-411 (9 pages).

El Diwani, G.; El Rafie, S., (2008). Modification of thermal and oxidative properties of biodiesel produced from vegetable oils. Int. J. Environ. Sci. Tech., 5 (3), 391-400 (10 pages).

Gharbani, P.; Tabatabaii, S. M.; Mehrizad, A., (2008). Removal of Congo red from textile wastewater by ozonation. Int. J. Environ. Sci. Tech., 5 (4), 495-500 (6 pages).

Giri, R. R.; Ozaki, H.; Ishida, T.; Takanami, R.; Taniguchi, S., (2007). Synergy of ozonation and photocatalysis to mineralize low concentration 2,4-dichlorophenoxyacetic acid in aqueous solution. Chemosphere, 66 (9), 1610 1617 (8 pages).

Giri, R. R.; Ozaki, H.; Taniguchi, S.; Takanami, R., (2008). Photocatalytic ozonation of 2, 4-dichlorophenoxyacetic acid in water with a new $\mathrm{TiO}_{2}$ fiber. Int. J. Environ. Sci. Tech., 5 (1), 17-26 (10 pages).

Ikehata, K.; Naghashkar, N. J.; El-Din, M. G., (2006). Degradation of aqueous pharmaceuticals by ozonation and advanced oxidation processes: A review. Ozone Sci. Eng., 2(6),353-414 (62 pages).

Jasim, S. Y.; Irabelli, A.; Yang, P.; Ahmed, S.; Schweitzer, L. (2006). Presence of pharmaceuticals and pesticides in Detroit River water and the effect of ozone on removal. Ozone Sci. Eng., 28 (6), 415-423 (9 pages).

Kim, I. H.; Tanaka, H.; Iwasaki, T.; Takubo, T.; Morioka, T.; Kato, Y., (2008). Classification of the degradability of 30 pharmaceuticals in water with ozone, $\mathrm{UV}$ and $\mathrm{H}_{2} \mathrm{O}_{2}$. Water Sci. Tech., 57 (2), 195-200 (6 pages).

Lange, F.; Cornelissen, S.; Kubac, D.; Sein, M. M.; Sonntag, J. V.; Hannich, C. B.; Golloch, A.; Heipieper, H. J.; Moder, M.;
Sonntag, C. V., (2006). Degradation of macrolide antibiotics by ozonation: A mechanistic case study with clarithromycin. Chemosphere, 65 (1), 17-23 (7 pages).

Lin, A. Y.; Reinhard, M., (2005). Photodegradation of common environmental pharmaceuticals and estrogens in river water. Environ. Toxicol. Chem., 24 (6), 1303-1309 (7 pages).

Malakootian, M.; Nouri, J.; Hossaini, H., (2009). Removal of heavy metals from paint industry's wastewater using Leca as an available adsorbent. Int. J. Environ. Sci. Tech., 6 (2), 183-190 (8 pages).

Pereira, V. J.; Linden, K. G.; Weinberg, H. S., (2007a). Evaluation of UV irradiation for photolytic and oxidative degradation of pharmaceutical compounds in water. Water Res., 41 (19), 4413-4423 (11 pages).

Pereira, V. J.; Weinberg, H. S.; Linden, K. G.; Singer, P. C. (2007b). UV degradation kinetics and modeling of pharmaceutical compounds in laboratory grade and surface water via direct and indirect photolysis at $254 \mathrm{~nm}$. Environ. Sci. Tech., 41 (5), 1682-1688 (7 pages).

Rosal, R.; Rodriguez, A.; Gonzalo, M. S.; Gracia-Calvo, E. (2008). Catalytic ozonation of naproxen and carbamazepine on titanium dioxide. Appl. Catal. B, 84 (1-2), 48-57 (10 pages).

Samarghandi, M. R.; Nouri, J.; Mesdaghinia, A. R.; Mahvi, A. H.; Naseri, S.; Vaezi, F., (2007). Efficiency removal of phenol, lead and cadmium by means of $\mathrm{UV} / \mathrm{TiO}_{2} / \mathrm{H}_{2} \mathrm{O}_{2}$ processes. Int. J. Environ. Sci. Tech., 4 (1), 10-25 (16 Pages).

Snyder, S. A.; Wert, E. C.; Rexing, D. J.; Zegers, R. E.; Drury, D. D., (2006). Ozone oxidation of endocrine disruptors and pharmaceuticals in surface water and wastewater. Ozone Sci. Eng., 28 (6), 445-460 (16 pages).

Ternes, T. A.; Stuber, J.; Herrmann, N.; McDowell, D.; Ried, A.; Kampmann, M.; Teiser, B., (2003). Ozonation: a tool for removal of pharmaceuticals, contrast media and musk fragrances from wastewater? Water Res., 37 (8), 1976-1982 (7 pages).

Vogna, D.; Marotta, R.; Napolitano, A.; Andreozzi, R.; d’lschia, M., (2004). Advanced oxidation of the pharmaceutical drug diclofenac with $\mathrm{UV} / \mathrm{H}_{2} \mathrm{O}_{2}$ and ozone. Water Res., 38 (2), 414-422 (9 pages).

\section{AUTHOR (S) BIOSKETCHES}

Giri, R. R., Ph.D., Researcher, New Industrial R and D Center, Osaka Sangyo University, 3-1-1 Nakagaito, Daito City, 574-8530 Osaka, Japan. Email: rabindra@cnt.osaka-sandai.ac.jp

Ozaki, H., D.Eng., Professor, Department of Civil Engineering, Osaka Sangyo University, 3-1-1 Nakagaito, Daito City, $574-8530$ Osaka, Japan. Email: ozaki@ce.osaka-sandai.ac.jp

Ota, S., Undergraduate Student, School of Engineering, Osaka Sangyo University, 3-1-1 Nakagaito, Daito City, 574-8530 Osaka, Japan. Email: s04k014@sub.osaka-sandai.ac.jp

Takanami, R., M.Eng., Researcher, New Industrial R and D Center, Osaka Sangyo University, 3-1-1 Nakagaito, Daito City, 574-8530 Osaka, Japan. Email: r-nami@cnt.osaka-sandai.ac.jp

Taniguchi, S., M.Eng., Researcher, New Industrial R and D Center, Osaka Sangyo University, 3-1-1 Nakagaito, Daito City, 574-8530 Osaka, Japan. Email: taniguch@cnt.osaka-sandai.ac.jp

How to cite this article: (Harvard style)

Giri, R. R.; Ozaki, H.; Ota, S.; Takanami, R.; Taniguchi, S., (2010). Degradation of common pharmaceuticals and personal care products in mixed solutions by advanced oxidation techniques. Int. J. Environ. Sci. Tech., 7 (2), 251-260. 